\title{
BIOLOGICAL ACTIVITIES OF NOVEL IN VITRO RAISED STEVIA PLANT
}

\author{
NEETA RAJ SHARMA ${ }^{1}$, VINEET MESHRAM ${ }^{2}$, MAHITI GUPTA ${ }^{1 *}$
}

${ }^{1}$ Department of Biotechnology, Lovely Professional University, Phagwara, Punjab, India. ${ }^{2}$ Department of Biochemistry, DAV University, Jalandhar, Punjab, India. Email: mahitigupta@gmail.com

Received: 12 April 2017, Revised and Accepted: 06 May 2017

ABSTRACT

Objective: This communication explores a lead fraction from methanolic extract of novel Stevia species raised under in vitro conditions for its various biological activities.

Methods: The dried Stevia leaves were crushed in methanol to get the polar extract. This methanol extract was tested for pancreatic lipase and alpha-amylase inhibitory activity using quantitative plate assays. Antibacterial property of the extract was also evaluated against Staphylococcus epidermidis, Escherichia coli, Bacillus subtilis, Staphylococcus aureus, and Pseudomonas aeruginosa. Further, the antioxidant potential was evaluated using 1,1-diphenyl-2-picrylhydrazyl.

Results: The methanolic extract inhibited pancreatic lipase with $\mathrm{IC}_{50}$ of $5.74 \mu \mathrm{g} / \mathrm{ml}$ in a similar manner to a well-known anti-obesity drug in the market orlistat. The methanolic extract also showed a better pancreatic $\alpha$-amylase inhibitory activity $\left(\mathrm{IC}_{50}=88 \mu \mathrm{g} / \mathrm{ml}\right)$ than acarbose. Further, the lead fraction exhibited $88.48 \%$ antioxidant activity. It also exhibited broad spectrum antimicrobial activity against the spectrum of Gram-positive and Gram-negative bacteria tested under laboratory conditions with a minimal inhibitory concentration ranging from 1.95 to $31.25 \mu \mathrm{g} / \mathrm{ml}$

Conclusion: Thus, this study signifies the vast potential of the lead fraction from a novel Stevia species for further development into a herbal formulation for prevention of various infectious and non-infectious diseases.

Keywords: Antioxidants, Enzyme inhibitor, Minimal inhibitory concentration, Stevia.

(C) 2017 The Authors. Published by Innovare Academic Sciences Pvt Ltd. This is an open access article under the CC BY license (http://creativecommons. org/licenses/by/4. 0/) DOI: http://dx.doi.org/10.22159/ajpcr.2017.v10i8.19117

\section{INTRODUCTION}

Obesity is a daunting health problem which occurs due to an imbalance between calorie uptake and utilization. Today obesity is becoming the major cause of preventable deaths, both in developed and developing nations [1]. It has been reported by World Health Organization (WHO) that every third individual around the globe is obese. It was previously known as disorder but recently WHO has declared it as a disease [2]. Pancreatic lipase is the major contributing enzyme that starts lipid metabolism by acting on triacylglycerides and resulting in the formation of monomers that are absorbed and accumulated in the body resulting to obesity. As action of pancreatic lipase is inhibited, most of the triacylglycerides are not converted to their simpler forms and hence are excreted out of the body [3]. Further, the most common disease related to obesity is Type 2 diabetes. Obesity and diabetes are two interlinked global health problems. Degradation of starch into sugars by $\alpha$-amylase leads to increased postprandial hyperglycemia. Hence, inhibiting the action of $\alpha$-amylase is the best way to control diabetes [4]. The current armamentarium of drugs available for the treatment of obesity suffers from various unwanted effects including fecal urgency, oily stools, abdominal cramps, flatulence, and oozing of oil from the anus leading to oily spotting [1]. Thus, there is an utmost requirement for exploring alternate avenues for development of new drugs for the treatment of these diseases with less or no side effects. Presently, there has been a lot of emphases given on the development of novel drugs from natural products due to their lesser antigenicity [5].

Stevia, commonly known as honey leaf or sweet leaf plant is a small perennial herb of South American origin belonging to the Asteraceae family [6]. Recent scientific trails have shown that leaves of Stevia possess broad spectrum antimicrobial, antiviral, and antifungal properties [7,8]. Further, the leaves of the plant also possess antihypertensive [9], antihyperglycemic [10], antitumor [7], and immunomodulatory effects [11]. Recently, Stevia grown under laboratory condition exhibited the presence of steviosides such as glycosides, steviosides, and rebaudioside. The ethanolic extract of these plants exhibited various medicinal properties including antioxidant and antimicrobial property [12]. Stevia plant contains a well-known non calorie natural sweetener stevioside [13]. Non calorie sweeteners are potential agents for obesity management [14] as they reduce the calorie intake of sugars. However, there exist very scanty reports on exploration of Stevia for anti-obesity properties. This is the first report of Stevia extract inhibiting pancreatic lipase with a potential similar to orlistat. Here in this study, we report the potential of a lead fraction obtained from a methanolic extract of in vitro raised Stevia plant for anti-obesity and antidiabetes, antioxidant, and antimicrobial activity leading to safer solution of obesity and diabetes management by a natural herbal agent with possible fewer side effects.

\section{METHODS}

Procurement of plant sample and preparation of lead fraction In vitro raised novel Stevia strain was procured from GVS Biotech Pvt. Ltd., Punjab, India. The leaves of the Stevia plant were air dried at $37^{\circ} \mathrm{C}$ and crushed into a fine powder using pestle mortar. Further, $2 \mathrm{~g}$ of the powdered leaves was extracted using methanol (Merck GR, USA) over a rotatory shaker for $16-18 \mathrm{hrs}$ at $130 \mathrm{rpm}, 28 \pm 1^{\circ} \mathrm{C}$. The solvent was filtered using Whatman filter Paper 1 . The solvent was completely evaporated, and the leftover extract was reconstituted in dimethyl sulfoxide (DMSO) (Merck GR, USA). The crude extract was tested for its various biological activities.

Dose response activity of methanolic extract of Stevia against pancreatic lipase

In vitro pancreatic lipase inhibitory activity was evaluated using a slight modified protocol described by Gupta et al. [1]. Varying concentrations 
of Stevia formulation ranging from 20 to $120 \mu \mathrm{g} / \mathrm{ml}$ were pre-incubated with $20 \mu \mathrm{l}$ of porcine pancreatic lipase $(40 \mathrm{U})$ at $37^{\circ} \mathrm{C}$ for $1 \mathrm{hr}$. Then, $100 \mu \mathrm{l}$ of $p$-nitrophenyl laurate (PNPL) $(2 \mathrm{mM})$ was added to start the reaction. The volume was made up to $250 \mu \mathrm{l}$ using Tris buffer ( $\mathrm{pH}$ 7.4). The plate was then subsequently incubated at $37^{\circ} \mathrm{C}$ for $3 \mathrm{hrs}$. The reading of the 96-well plate was measured at $410 \mathrm{~nm}$ using a 96-well plate reader. Orlistat was used as a positive control whereas negative control only comprised enzyme and PNPL.

\section{In vitro pancreatic amylase inhibition assay}

Inhibition of pancreatic amylase by Stevia formulation was done according to modified protocol [15]. All the concentrations were reduced to $300 \mu \mathrm{l}$, and the test was performed in 96-well plate. In this assay, acarbose served as positive control.

\section{In vitro assay for anti-oxidant activity}

The free radical scavenging property of methanolic extract of Stevia was determined by recording the change in the optical density of the 1,1-diphenyl-2-picrylhydrazyl (DPPH) radicals (DPPH, Sigma-Aldrich, USA). Briefly, to $1 \mathrm{ml}$ of DPPH (100 uM), $50 \mu \mathrm{l}$ of extract $(1 \mathrm{mg} / \mathrm{ml})$ was added and incubated at $37^{\circ} \mathrm{C}$ for half an hour. Further, the absorbance was recorded at wavelength $517 \mathrm{~nm}$ using a ultraviolet-visible (UV-visible) spectrophotometer (Hitachi U-2900, Japan). Both positive (gallic acid) and negative (DMSO) controls were used in assay [16].

Free radical scavenging activity was calculated as:

$$
\% \text { Free radical scavenging }=\left[\frac{\mathrm{OD} \text { control }-\mathrm{OD} \text { test }}{\mathrm{OD} \text { control }}\right] \times 100
$$

Total phenolic content of methanol extract

Total phenol content of the mixture was estimated using Folin-Ciocalteu reagent based assay using gallic acid as standard. The methanolic extract $(1 \mathrm{mg} / \mathrm{ml})$ was mixed with $500 \mu \mathrm{l}$ (HiMedia, Mumbai, India) of Folin-Ciocalteu reagent followed by addition of $1.5 \mathrm{ml}$ of $2 \%$ sodium carbonate (HiMedia, Mumbai, India). The final volume was made to $5 \mathrm{ml}$ using double distilled water. This mixture was then subsequently incubated at $37^{\circ} \mathrm{C}$ for half an hour. Using a UV-visible spectrophotometer, the absorbance was measured at $765 \mathrm{~nm}$. The total phenolic content was estimated from the regression equation: $y=0.026 x-0.008$ with $\mathrm{R}^{2}=0.99[16]$.

\section{In vitro broth dilution assay for minimal inhibitory concentration} (MIC) estimation

In vitro broth dilution assay to estimate MIC of the extract was performed as per described by Gomber and Saxena [17]. Briefly describing, $125 \mu \mathrm{l}$ of Mueller-Hinton broth was dispensed into each well. Subsequently, $50 \mu \mathrm{l}$ of $0.5 \mathrm{McFarland}$ adjusted $18 \mathrm{hrs}$ old test organisms were added into wells, and the plate was kept at $37^{\circ} \mathrm{C}$ for 2.5 hrs. Further, $25 \mu \mathrm{l}$ of the test extract (i.e., two-fold serial dilutions of concentrations between 62.5 and $0.48 \mu \mathrm{g} / \mathrm{ml}$ ) was dispensed into each well, and the plate was incubated at $37^{\circ} \mathrm{C}$ for $24 \mathrm{hrs}$. Further, $20 \mu \mathrm{l}$ of $0.02 \%$ of 3-(4,5-Dimethylthiazol-2-Yl)-2,5-diphenyltetrazolium bromide (MTT) was added, and the plate was again incubated at $37^{\circ} \mathrm{C}$ for 60 minutes. The change in color in the wells due to difference in antimicrobial activities from pink (live) to yellow (dead) was observed and MIC was calculated. All the tests were performed in triplicates.

\section{RESULTS}

Dose response activity of methanolic extract of Stevia against pancreatic lipase

The quantitative plate assay ascertained the reduced pancreatic lipase activity by the methanolic extract of novel Stevia sp. and the only lipase inhibitor orlistat. Stevia extract inhibited pancreatic lipase with an $\mathrm{IC}_{50}$ of $2.7 \mu \mathrm{g} / \mathrm{ml}$ which was quite comparable to orlistat $\left(\mathrm{IC}_{50}=5.7 \mu \mathrm{g} / \mathrm{ml}\right)$. The inhibition pattern of Stevia extract was also similar to orlistat (Fig. 1).
In vitro pancreatic $\alpha$-amylase inhibitory activity of methanolic extract of Stevia

This study showed the greater potential of Stevia species for inhibition of pancreatic amylase. The $\mathrm{IC}_{50}$ value of the methanolic extract was found to be $88 \mu \mathrm{g} / \mathrm{ml}$ as compared to that acarbose $\left(\mathrm{IC}_{50}=91.1 \mu \mathrm{g} / \mathrm{ml}\right.$ ) (Fig. 2).

In vitro assay for antioxidant activity of methanolic extract of Stevia The methanolic extract of Stevia in the DPPH assay exhibited $87.48 \pm 2.08 \%$ antioxidant activity which was better than as compared to standard gallic acid which showed $84.16 \pm 1.49 \%$ antioxidant activity. There was a noticeable change in color from purple to yellow following scavenging reaction. Further, the total phenolic content of the lead fraction amounts to $21.42 \mu \mathrm{g} / \mathrm{ml}$.

\section{In vitro broth dilution assay for MIC estimation}

The methanolic extract of in vitro raised Stevia exhibited better MIC value (1.95-3.91 $\mathrm{\mu g} / \mathrm{ml})$ for Staphylococcus epidermidis, Escherichia coli, and Bacillus subtilis whereas it showed higher MIC values (15.625$31.25 \mu \mathrm{g} / \mathrm{ml}$ ) for Staphylococcus aureus and Pseudomonas aeruginosa when compared to streptomycin under in vitro conditions (Table 1).

\section{DISCUSSION}

Stevia is a safe, calorie-free, and natural sweetener with no side effects and it is also considered as a potential antidiabetic supplement also

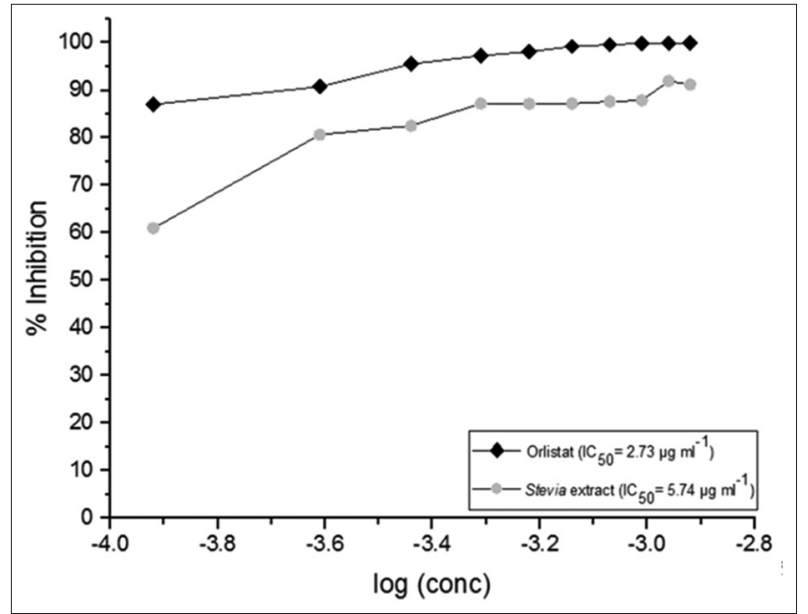

Fig. 1: Dose-response curves for inhibition of pancreatic lipase by Stevia formulation. Orlistat served as positive control

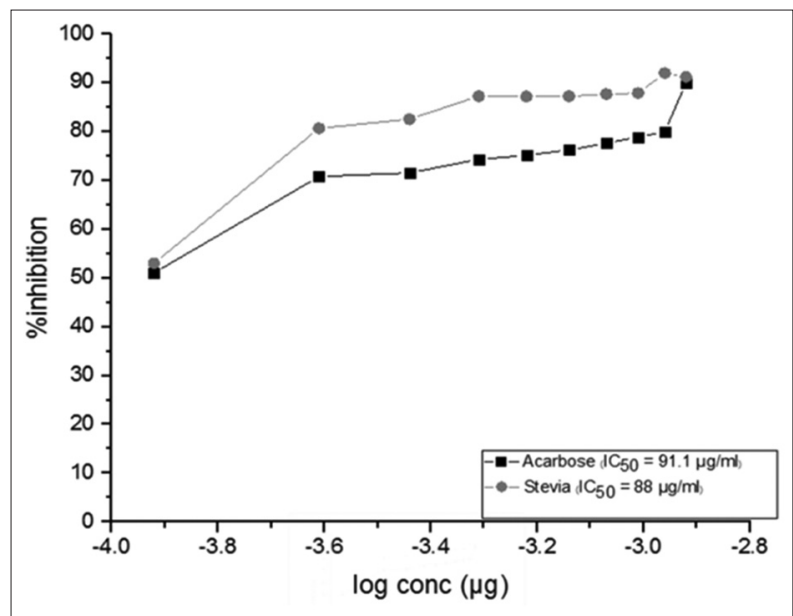

Fig. 2: Dose-response curve for inhibition of $\alpha$-amylase by Stevia extract. Acarbose served as positive control 
Table 1: MIC of methanolic Stevia extract and streptomycin against Gram-positive and Gram-negative bacteria

\begin{tabular}{lll}
\hline \multirow{2}{*}{ Test organism } & MIC in $\mu \mathrm{g} / \mathbf{m l}$ \\
\cline { 2 - 3 } & Stevia extract & Streptomycin \\
\hline Staphylococcus aureus & $15.62^{*}$ & 7.18 \\
Staphylococcus epidermidis & $3.91^{*}$ & 7.81 \\
Escherichia coli & 1.95 & 3.91 \\
Bacillus subtilis & 1.95 & 3.91 \\
Pseudomonas aeruginosa & $31.25^{*}$ & 15.625 \\
\hline
\end{tabular}

${ }^{*} \mathrm{p}<0.05$ (Tukey's post hoc analysis). MIC: Minimal inhibitory concentration

possessing antioxidant and antimicrobial properties [18,19]. There are over 240 species of Stevia, and they have been largely focussed on their sweetening properties and in the development antidiabetic agent [20]. Apart from this, several studies have been carried which determined in vitro antimicrobial, anticancer, antioxidant, and anticancer properties of the Stevia plant [6]. However, very few or almost no efforts have been made to explore the lipase inhibitory (anti-obesity) activity and correlate it with the antidiabetic property of the plant. There exists only one report regarding pancreatic lipase inhibitory activity of Stevia rebaudiana [21]. Since obesity and diabetes are interrelated; this would be a novel avenue for management of two of the most threatening disease of the modern world. In this context, we chose to evaluate both the anti-obesity and antidiabetic property of the in vitro raised Stevia plant. The study was focussed on inhibition of two enzymes, viz., pancreatic lipase and $\alpha$-amylase for anti-obesity and antidiabetic property, respectively $[1,4]$. The lipase inhibitory property of the methanolic extract of in vitro raised Stevia plant $\left(\mathrm{IC}_{50}=5.74 \mu \mathrm{g} / \mathrm{ml}\right)$ in this study was found to be much better than that observed in Stevia $\left(\mathrm{IC}_{50}=530 \mu \mathrm{g} / \mathrm{ml}\right)$ [21]. Pancreatic lipase inhibitory potential of the lead fraction was better than hesperidin and carnosic acid isolated from citrus fruits and Salvia officinalis, respectively [22,23]. It is believed that further purification of the methanolic fraction will increase the inhibition response, which would further able to demonstrate exact IC of the purified compound [1]. Similar pattern was observed in several microbial lipase inhibitors such as vibralactone and Percy Quin whose phospholipids inhibitory efficiency increased on purification [24,25].

Alpha-amylase is a key enzyme which is accountable for degradation of starch into monosaccharides. Alpha-amylase hydrolyses complex sugar molecules into simpler sugars that are absorbed by the villi of small intestine, hence passing into the hepatic portal vein. These sugars are responsible for increase in postprandial glucose levels. The inhibitors of alpha-amylase have been given another name as starch blockers because they prevent absorption of dietary starch in the body ultimately lowering postprandial glucose levels [26]. The lead fraction in this study also exhibited comparable $\alpha$-amylase inhibitory activity. In this study, the $\alpha$-amylase inhibitory activity $\left(\mathrm{IC}_{50}=88 \mu \mathrm{g} / \mathrm{ml}\right)$ was found to be far better than aqueous extracts of $S$. rebaudiana reported by Ruiz-Ruiz et al. [15] and Patil et al. [27]. The extract might exhibit amylase inhibitory activity by binding at substrate binding site/active site of alpha-amylase, an enzyme responsible for the breakdown of $\alpha-1,4$ glycosidic bonds in starch and other polysaccharides that increase the sugar level in body and subsequently leading to postprandial hyperglycemia. Therefore, this report supports the theory that moieties from medicinal plants having a potential to inhibit $\alpha$-amylase can be used as a pharmacophore for managing postprandial hyperglycemia with minimal side effects [15].

Calculation of MIC using MTT is a widely known precise technique to estimate the response of a microorganism to a specific antibiotic [28]. This study reports the potential of methanolic fraction of Stevia plant to inhibit $S$. epidermidis, E. coli, and B. subtilis with a lower MIC value $(1.95-3.91 \mu \mathrm{g} / \mathrm{ml})$ whereas it displayed higher MIC value $(15.62-31.25 \mu \mathrm{g} / \mathrm{ml})$ for $S$. aureus and P. aeruginosa when compared to streptomycin. The antibacterial property reported in this study is far better than the earlier studies reporting MIC of $S$. rebaudiana against B. subtilis and E. coli to be $500 \mathrm{mg} / \mathrm{ml}$ [29]. Earlier studies have also reported that the aqueous and ethanolic extract of Stevia possesses broad spectrum antimicrobial activity against microorganisms such as S. aureus, S. epidermidis, B. subtilis, and P. aeruginosa. Stevia has been known to possess antibacterial, antifungal, and antiviral properties [30]. Further, the lead fraction also exhibited strong antioxidant activity via free radical scavenging activity. The antioxidant activity of this methanolic extract (88.48\%) was better than that of antioxidant activity reported from earlier Stevia extract $(71.75 \%$ and $86.4 \%)$ [12,31]. Following scavenging reaction, there was a noticeable change in color from purple to yellow. The change in color was due to the reaction of the extract with the antioxidant molecule which ultimately resulted in the scavenging of the radical by hydrogen donation [12]. Stevia has been reported to have antioxidant and antidiabetic properties in diabetic mice [32]. Thus, the Stevia plant offers to be a promising source of bioactive compounds with efficient medicinal properties. To date, there are no reports on determination of lipase inhibitory and $\alpha$-amylase inhibitory activity from an extract of in vitro grown Stevia plant. This study is the pioneering work where the lipase and $\alpha$-amylase inhibitory activities of the methanolic extract of Stevia plant along with potential antioxidant and antimicrobial activities were explored.

\section{CONCLUSION}

In vitro raised novel strain of Stevia plant contains a potential pharmacophore which can be used as an herbal formulation for a safer management of obesity and related diseases. Market today needs a natural drug for the two most prevailing and interrelating diseases. Purification, structural and biochemical characterization of the bioactive compound in the lead extract will lead to a natural drug for obesity and diabetes management.

\section{ACKNOWLEDGMENTS}

The authors are thankful to Lovely Professional University, Punjab, India, for providing the infrastructure to carry out the work. Authors also thank GVS Biotech Pvt. Ltd., Punjab, India, for providing plant material.

\section{REFERENCES}

1. Gupta M, Saxena S, Goyal D. Potential pancreatic lipase inhibitory activity of an endophytic Penicillium species. J Enzyme Inhib Med Chem 2015;30(1):15-21.

2. World Health Organization. Global Health Observatory Data, Risk Factors. This is Present in World Health Organization Fact Sheets WHO; 2015. Available from: http://www.who.int/mediacentre/factsheets/fs311/en.

3. Lunagariya NA, Patel NK, Jagtap SC, Bhutani KK. Inhibitors of pancreatic lipase: State of the art and clinical perspectives. EXCLI J 2014;13:897-921.

4. Rahimzadeh M, Jahanshahi S, Moein S, Moein MR. Evaluation of alpha - Amylase inhibition by Urtica dioica and Juglans regia extracts. Iran J Basic Med Sci 2014;17(6):465-9.

5. Cragg GM, Newman DJ. Natural products: A continuing source of novel drug leads. Biochim Biophys Acta 2013;1830(6):3670-95

6. Gupta E, Purwar S, Sundaram S, Rai GK. Nutritional and therapeutic values of Stevia rebaudiana: A review. J Med Plant Res 2013;7(46):3343-53.

7. Jayaraman S, Manoharan MS, Illanchezian S. In-vitro antimicrobial and antitumor activities of Stevia rebaudiana (Asteraceae) leaf extracts. Trop J Pharm Res 2008;7(4):1143-9.

8. Kedik SA, Yartsev EI, Stanishevskaya IE. Antiviral activity of dried extract of Stevia. Pharm Chem J 2009;43(4):198-9.

9. Hsieh MH, Chan P, Sue YM, Liu JC, Liang TH, Huang TY, et al. Efficacy and tolerability of oral stevioside in patients with mild essential hypertension: A two-year, randomized, placebo-controlled study. Clin Ther 2003;25(11):2797-808.

10. Benford DJ, DiNovi M, Schlatter J. Safety evaluation of certain food additives: Steviol glycosides. WHO Food Addit Ser 2006;5:117-44.

11. Chatsudthipong V, Muanprasat C. Stevioside and related compounds: Therapeutic benefits beyond sweetness. Pharmacol Ther 2009;121(1):41-54. 
12. Ramya M, Manogaran S, Joey K, Katherasan S. Studies on biochemical and medicinal properties of Stevia rebaudiana grown in vitro. Int J Res Ayurveda Pharm 2014;5(2):169-74.

13. Geuns JM. Stevioside. Phytochemistry 2003;64(5):913-21.

14. Mohd-Radzman NH, Ismail WI, Adam Z, Jaapar SS, Adam A. Potential roles of Stevia rebaudiana Bertoni in abrogating insulin resistance and diabetes: A Review. Evid Based Complement Alternat Med 2013;2013:718049.

15. Ruiz-Ruiz JC, Moguel-Ordoñez YB, Matus-Basto AJ, SeguraCampos MR. Antidiabetic and antioxidant activity of Stevia rebaudiana extracts (Var. Morita) and their incorporation into a potential functional bread. J Food Sci Technol 2015;52(12):7894-903.

16. Yadav M, Yadav A, Yadav JP. In vitro antioxidant activity and total phenolic content of endophytic fungi isolated from Eugenia jambolana Lam. Asian Pac J Trop Med 2014;7S1:S256-61.

17. Gomber C, Saxena S. Anti-staphylococcal potential of Callistemon rigidus. Cent Eur J Med 2007;2(1):79-88.

18. Geuns JM, Buyse J, Vankeirsbilck A, Temme L. The safety of stevioside used as a sweetener. J Food Agric Environ 2004;2:290-1.

19. Thomas JE, Glade MJ. Stevia: It's not just about calories. Open Obes 2010;2:101-9.

20. Campos MS, Martin EB, Basto AM, Amaro DC, Olmedo MM, Ordones YM, et al. Comparison of chemical and functional properties of Stevia rebaudiana (Bertoni) varieties cultivated in Mexican Southeast. Am J Plant Sci 2015;5:286-93.

21. Adisakwattana S, Intrawangso J, Hemrid A, Chanathong B, Makynen K. Edible plant extracts for treatment of hyperlipidaemia. Food Technol Biotechnol 2012;50(1):11-6.

22. Kawaguchi K, Mizuno T, Aida K, Uchino K. Hesperidin as an inhibitor of lipases from porcine pancreas and Pseudomonas. Biosci Biotechnol Biochem 1997;61(1):102-4.

23. Ninomiya K, Matsuda H, Shimoda H, Nishida N, Kasajima N,
Yoshino T, et al. Carnosic acid, a new class of lipid absorption inhibitor from sage. Bioorg Med Chem Lett 2004;14(8):1943-6.

24. Hopmann C, Kurz M, Mueller G, Toti L. Percyquinnin, a Process for its Production and its use as a Pharmaceutical. US Patent No. US6596518 B2; 2003.

25. Liu DZ, Wang F, Liao TG, Tang JG, Steglich W, Zhu HJ, et al. Vibralactone: A lipase inhibitor with an unusual fused beta-lactone produced by cultures of the Basidiomycete boreostereum vibrans. Org Lett 2006;8(25):5749-52.

26. Uddin N, Hasan MR, Hossain MM, Sarker A, Hasan AH, Islam AF, et al. In vitro $\alpha$-amylase inhibitory activity and in vivo hypoglycemic effect of methanol extract of Citrus macroptera. Montreal Fruit Asian Pac J Trop Biomed 2014;4(6):473-9.

27. Patil S, Raunekar V, Laware S. Comparative in vitro $\alpha$-amylase inhibitory activity of four indigenous antidiabetic plants. Indo Am J Pharm Res 2015;5:741-6.

28. Meshram V, Kapoor N, Saxena S. Muscodor kashayum sp. Nov. - A new volatile anti-microbial producing endophytic fungus. Mycology 2013;4(4):196-204.

29. Singh S, Garg V, Yadav D, Beg MN, Sharma N. In vitro antioxidative and antibacterial activities of various parts of Stevia rebaudiana (Bertoni). Int J Pharm Pharm Sci 2012;4(3):468-73.

30. Snehal P, Madhukar K. Quantitative estimation of biochemical content of various extracts of Stevia rebaudiana leaves. Asian J Pharm Clin Res 2012;5(1):115-7.

31. Ruiz Ruiz JC, Moguel Ordoñez YB, Matus Basto Á, Segura Campos MR. Antioxidant capacity of leaf extracts from two Stevia rebaudiana Bertoni varieties adapted to cultivation in Mexico. Nutr Hosp 2014;31(3):1163-70.

32. Singh S, Garg V, Yadav D. Antihyperglycemic and antioxidative ability of Stevia rebaudiana (Bertoni) leaves in diabetes induced mice. Int $\mathrm{J}$ Pharm Pharm Sci 2013;5(2):297-302. 